\title{
Inductive/Deductive Learning by Considering the Role of Gender-A Case Study of Iranian French-Learners
}

\author{
Rouhollah Rahmatian ${ }^{1}$ \& Fatemeh Zarekar ${ }^{1}$ \\ ${ }^{1}$ Faculty of Humanities, Tarbiat Modares University, Tehran, Iran \\ Correspondence: Rouhollah Rahmatian, Faculty of Humanities, Tarbiat Modares University, Tehran, 14115-111, \\ Iran. Tel: 98-21-8288-4648. E-mail: rahmatir@modares.ac.ir
}

Received: June 20, 2016

doi:10.5539/ies.v9n12p254
Accepted: July 26, $2016 \quad$ Online Published: November 27, 2016

URL: http://dx.doi.org/10.5539/ies.v9n12p254

\begin{abstract}
This article defines the objective of discovering the first preferred styles of Iranian learners of French as a Foreign Language (FFL) as regards inductive or deductive learning; and secondly, the difference between gender-based learning tendencies. Considering these points as target variables, the questionnaire developed by Felder and Silverman in 1988 was applied to form the learning styles and consequently to associate them with inductive and deductive approaches. The results led the team to set the idea which is based on the choice of induction or deduction in language learning and the gender variable that follows different directions. Consequently, in terms of the inductive approach, we find ourselves facing a rather male solicitation. A proportion of the use of this approach is also associated with women whose motivation is seen rather noticeably. Moreover, the significance is relative rather than significant in all the relationships studied in this research: males and inductive (1)/deductive learning (2); females and inductive (3)/deductive learning (4); inductive (5)/deductive (6) among Iranians.
\end{abstract}

Keywords: constructivism, deductive learning; gender, inductive learning, Iranian French learners, learning styles

\section{Introduction}

The starting point is that our teaching/learning has already an inductive or deductive approach by itself. Being presented as a real discovery approach, the induction was created by Aristotle who considered the transition from abstract to concrete in science. As known globally, inductive ways of learning are fortified by different kinds of our perception and this can be realized by our experiences. So, we think these experiences and inductive ways will be led by intelligence. This fact is also confirmed by Bodéüs in 2002, while speaking about Aristotle theories. In our context regarding the teaching/learning languages, the goal is to access the operation of the target language as an authentic possible way. Therefore, we are not dealing with the establishment of the universal laws; moreover, we do not share the idea that induction is always doubtful. In the apparently opposite approach, the deductive approach, validity or truth of the findings is preserved. With the deductive approach, as with the rationalists, the truth comes with pre-established logical concepts, while with the other, closer to empiricism (including the most advanced form of which was founded by Davide Hume regarding the empirical observation as a prerequisite for the genesis of the whole theory true or probably true), knowledge comes from experience and observation. Nevertheless, these two are not contradictory. In a more developed inductivism, we can claim that empiricism and rationalism intersect where the logic of truth will only be guaranteed by the role of the brain and its previous knowledge. Following Michel (2002), scientists try to rely on what has been already known and what is exploring in new areas.

We consider several and different adjectives for these two concepts, induction and deduction: inductive/deductive research, inductive/deductive thinker, inductive/deductive approach, inductive/deductive pedagogy, inductive/deductive teaching, inductive/deductive learning strategy, inductive/deductive reasoning. The first dichotomy exists in the world of science where objectivity in the theories is sought and it will be respected if we start with experience. Having applied two different worlds with each of the approaches, an objection was always noticed. Thus, as explained by Pellissier-Tanon (2001) the induction is derived from a constructivist movement and the other one is derived from a positivist thought.

We consider that in some constituted methods, the opposing methods are implemented successively. The same 
idea is confirmed by Puren (2001a). As we observe, Puren realize that the consistency in language teaching is defined by a direction from discovery of the rules to their implementation in practice. These indications lead us to have the same perception as Vincent and Lefrançois (2013), about the two approaches and to distinguish them according to their classification in things which are supposed to be presented, and the place of reflection is considered.

Moreover, saying that nowadays learners are situated at the center of pedagogical activities, it can be said that instead of inductive/deductive teaching we have inductive/deductive learning. It does not tend to neglect the important role of the teacher but, learning is a goal that does not justify the way.

The problematic of the research is that not only learning style of learners, in the Iranian context, is not considered as important in favor of how the teacher prefers to conduct their course, but also the option of a deductive approach, both among teachers and learners, fails to achieve the interest of a constructive teaching/learning.

We hypothesize that the inductive approach is less present in the teaching/learning of the FFL in Iran, due to the fact that both teachers and learners are not used to it. However, teachers, in this approach are afraid of being rejected by learners, they prefer to forget or apply it with caution while considering other factors such as the level and the item of language teaching.

Our goal is to emphasize what is combined directly with the teaching approach, that is to say learning styles. And so, following the four dimensions of Felder and Silverman (1988), we define the degree of significance of the relationships between them and the gender of learners. The second focus of this research is the presence of inductive and deductive approaches in the Iranian context learning FFL, by means of styles. These ones are considered as affective elements, once taken into consideration, increase the motivation that "[...] appears to be a prerequisite for successful learning of a foreign language" (Zhuya, 2011).

Research is carried out regarding this study only, in most cases the teaching/learning of grammar from the two approaches often contrasts. It is therefore the differences between the two, identified field studies. The novelty of our research lies in checking the gender variable that certainly plays a decisive role in any field.

\section{Review of the Literature}

\subsection{Deductive Method (Teacher-Centered Method)}

This "educational process" (Defays \& Deltour, 2003) or the "educational intervention" (Vincent \& Lefrançois, 2013), considered as "[...] a traditional [and] instructional approach, which focused on the form first" (Dekeyser, 1998; Doughty \& Williams, 1998a; Robinson, 2001; cited by Haight et al., 2007), is summed up in a declarative knowledge of the transition to the so-called procedural. According to a common definition of the approach, we mention a reflection of a teacher about his job. We find that Xin (2012) explains this idea as a deductive instruction that may be learned when target language is becoming complex. While Besse (1985), inspired by John Locke stated that the routine precedes the rules. Otherwise, we find Puren (2001a), who says that the rules come before examples and activities that learners can do by linking to the explanations explicitly. This makes us think about meaningful learning that would be realized with induction. That is to say that the fact that two approaches within the cognitive approach do not seem strange.

Although we were not going in the same direction with what we want to imply by inductive/deductive learning, the dichotomy we reported last among those set out in the introduction, should be briefly considered: inductive/deductive reasoning. Deductive reasoning is grouped into two classes that are conditioned reasoning (if $\rightarrow$ then) which is from inference strategy, and reasoning through the syllogism. Concerning the last one, we start from two introductions to achieve the result, which is sometimes unreachable. What matters to be reported with any kind of reasoning is that it requires mental activity and calls reflection. Always being in an institutional or academic grade of language learning, deductive reasoning, despite all our emphasis on deductive teaching/learning in our tradition, does not find its right place. It is seen as a cognitive component of which we have stated; especially as in a deductive process, knowledge already made has to be transmitted by teacher or professor.

In sum, we could claim that with the deduction, we are dealing with receptors of rules that become potential users. Indeed, the cognitive activity cannot be neglected, which does not always mean the reasoning involved in inferring conclusions about the functioning of the current question. So we want to eliminate the passivity we are talking about with this method. 


\subsection{Inductive Method (Student-Centered Method) and Learning by Problem Solving}

The inductive method, "[...] focused first on a specific function of the language linked to a specific content and meaning" (Dekeyser, 1998; Doughty \& Williams, 1998a; Robinson, 2001; quoted in Haight et al., 2007) consists in observing the real phenomenon to draw the way in which it was governed. According to Decoo (1996, cited by Vincent \& Lefrançois, 2013) it is defined by four terms for which there are no further discussions: "inductive approach guided by conscious discovery, inductive approach followed by a summary explicit explanation, implicit inductive approach using structured materials, implicit inductive approach without using structured materials. What is important with the inductive approach, or better to say, ensuring the truth of what is retained from observations and verification, is repetition. For this, we would stress the observation body whose lack or insufficiency will lower the value of the results. So, it is a probabilistic approach. The accuracy of final formulations leaves room for the questioning and challenges later. There are two necessary conditions: sufficient observations and sufficiently varied conditions. However, it is always expected to find some or other examples, like Goodman (1946) which he described as "grue" and called the paradox of Goodman green until a certain date, and then blue".

Induction, going in the same path as (A) Francis Bacon (the founder of modern empiricism), (B) Auguste Comte (the founder of modern sociology), (C) Claude Bernard (the inventor of the method OHERIC (Roland, 2014): observation, Hypothesis, Experiment, Results, Interpretation, Conclusion) and (D) Karl Popper, to whom we refer when speaking of this approach is represented as follows respectively:

(A) A rather immature method that its result could be refuted once appeared on a contradictory case.

(B) Priority is given, with the induction, to the observation and we are in a positivism approach where laws are formulated from the experience of the real facts.

(C) A method from specific to the general.

(D) It is a fact which is inferred from the examples, which are well tested, and a transition to more universal event. Observation and experimentation are still present there.

As Musgrave confirms (2009), Popper is considered as a well-known deductivist. Because Popper thinks that every time we reason, we reason by a deductive manner, or following him, the best reconstructions are the result of reasoning deductively. He criticizes classical induction from an example of inference based on observations, the white swans. He admits that with the induction, we can never arrive to a general principle; therefore he replaces the induction by invalidation. His argument approves the criticism of Hume concerning the invalidity of induction. We conclude that there are logically no safe and certain results with this approach where the collection and testing hypotheses prevail.

"Inductive teaching methods come in any forms, including discovery learning, inquiry-based learning, problem-based learning, project-based learning, case-based teaching, and just-in-time teaching" (Prince \& Felder, 2007). A problem-solving learning would be a real construction of knowledge, because it is realized by the trial and error. Takimoto (2008) led his finding toward the inductive and problem-solving approaches by the fact that the inductive method can be realized when problem-solving and inductive approaches are combined. Such an idea is restudied by Alzu'bi (2015). However, solving problems is not limited only to the inductive approach. It is also confronted with the deductive approach but the difference lies in the fact that with the deduction, the concepts which are presented are so general that the problems to solve are not really a problem in the application of theories. On the contrary, the solution is looked for with the induction by searching through prior knowledge; which strengthens and makes declarative knowledge practical.

We believe, it would be better to insist on spiral teaching/learning, not only to say that both approaches applied in this research are complementary, but also to say that the inference (this cognitive strategy) could be the basis which induces the student while it does not guarantee the accuracy of acquired knowledge from observation and reasoning.

The reason that we insists on the inductive approach in cognitive planning is justified by the cognitivism finding which declares that integrated learning and new learning can both make the spiral acquisition. To have a look at the past for progress, it requests procedural support. So, as mentioned by Claude Bernard in his former book Introduction to the Study of Experimental Medicine, theories and concepts are used to support experimentation to make new practical phenomena. Furthermore, the two approaches are not in conflict with each other, while there are many studies and research which put them on a versus position. If we said at the start with naïve inductivism, that new experiences and observations lead to new knowledge and that without preconceptions or prejudgments, today, we stop to think about following the theoretical framework of behaviorism and pay more attention to the 
role of the brain as a guide to its contents accumulated after birth. In rules' detection from observations and subsequently assumptions, other discovery methods are activated as the technique of so-called accessibility discovery. This refers to the usage of the information which is available in memory, where there is proof for inductive and spiral learning. Thus, "[...] students can lay the foundations for their internal representation of the target language, which can allow effective learning to function properly" (Pica, 1994; quoted by Chalipa, 2013).

\subsection{Cognitivism and Constructivism}

Cognitivism is characterized by the cognition which is defined as any mental activity. Once cognition starts working, as explained by Griggs et al. (2002), knowledge was no longer thought os as a concept that is transmitted and then integrated, but as an active construction of all which is related to the mother tongue. The history of language teachingpresents " [...] two major methodological trends based on two antagonistic theories of learning: constructivism on one hand and behaviorism on the other [...]" (Tardieu, 2014). Constructivism which is based on cognitive psychology- founded by Piaget and developed by Vygotsky- puts the learner at the center of learning that should incorporate new things in his environment by manipulating and then thinking about it. Learning doesn't mean gathering information, but it concerns learning by doing. It's the question of different ways for developing skills specifically the performance to act for reaching the truth. That's why the aim of teaching is to make students learning how to learn. This idea is taken and used by Wong and Nunan in 2011. So, it would be an experience a posteriori that would require further practice as a cognitive strategy. And all the practical learning leads to as Alzu'bi (2015) states, a less passivity and interest after becoming tired.

A learner makes normally the learning operation following what he internalized before beginning a new system. He simplifies the learning process by making himself some hypotheses which have been already known. This idea is approved by the same process that Ellis (2008) presents in second language knowledge and knowledge of the world. The support of prior knowledge in inductive learning is not necessarily distorting, as it is a case in assimilation, and rather intensifying acquired knowledge makes it more durable.

\section{Learning Styles and Gender}

Strategies and learning styles are so important in choosing a teacher. We could argue that the link between teaching and learning is questionable in the sense that a good course elaboration does not guarantee good learning. Knowing these two very different areas and at the same time the fact that they are interwoven into each other, we will consider learning styles as the way they were formulated in Index of Felder and Silverman Learning Styles (ILS) in 1988.

This model, which was developed three years later by Felder in collaboration with psychologist Barbara A. Soloman, "[...] can be helpful for an instructor to know the distribution of learning styles in a class, the point is not to place all students into one or another style category and teach each student exclusively according to his or her preferred style" (Felder \& Henriques, 1995, p. 27). The original version, containing five dimensions with omitted inductive/deductive, was designed to explore the learning styles of engineering students to the teacher to better plan his course. The induction and deduction are organizational ways in presenting information. As Felder and Silverman have stated in their paper, "induction is the natural human learning style" and "deduction is the natural human teaching style" (1988).

On the preface of an article written with Linda K. Silverman in 1988, he added on 2002 that "Learning and teaching styles in engineering education". Felder explains why he omitted the dimension inductive/deductive from its model. Believing in inductive learning/teaching, he cites that the problem lies in the preferences of the learner to practice deduction. So, in order not to prescribe a specific model that would actually neither in the sense of acting teachers nor with the preferred style of learners, he omitted the dimension of induction/deduction from its categories. There is another change in the initial model and it is the replacement of the category "audience" by "verbal" in the third dimension (Table 1). 
Table 1. ILS dimensions (Boulton, 2010)

\begin{tabular}{|c|c|}
\hline Active & Reflexive \\
\hline Learning by experimenting, works well in a group. & $\begin{array}{l}\text { Learning by reflecting, prefers to work alone or with only one } \\
\text { regular partner. }\end{array}$ \\
\hline Sensing & Intuitive \\
\hline A practical reflection, practice-oriented facts and procedures. & $\begin{array}{l}\text { An abstract thinking, innovative, oriented toward theories and } \\
\text { subjacent senses. }\end{array}$ \\
\hline Visual & Verbal \\
\hline $\begin{array}{l}\text { Prefers visual representations of new information: ima } \\
\text { diagrams, graphs etc. }\end{array}$ & $\begin{array}{l}\text { Prefers verbal explanations - written or } \\
\text { Oral. }\end{array}$ \\
\hline Sequential & Global \\
\hline A linear thinking learns incrementally step by step. & A holistic thinking suddenly learns from an overview. \\
\hline
\end{tabular}

There are dimensions which are associated with each other. As stated by Silverman (2002), Felder and Spurlin (2005), Felder and Silverman (1988), there are associations between dimensions, which are lists in accordance with the cited references. Firstly, an association between the global and visual style, then between the sequential and verbal was introduced. Secondly, we stated an alternative relationship between first three dichotomies while the second and fourth are more related to each other. Finally, with Felder and Silverman (1988), is the induction which was removed from the model, and was concerned with the sensory style, in terms of motivation in learning.

These four dimensions of learning styles respectively are related to how the learner prefers to process information, perceive the way the information was presented to him, and finally, how he learns the information. Putting all other factors aside, there is a tendency for all learners, to reach their purposes as soon as possible, which it proves the presence of the deductive approach in all teaching/learning process. But in our research, this psychological model might help us decide the attribution of dimension that constitutes induction and deduction to learners' gender.

The emphasis on learning styles insists on the idea that students should apply in their learning, and this is somewhat increasingly fruitful. "Learning styles reflect preferences and tendencies; they are not infallible indicators of strengths or weaknesses in either the preferred or the less preferred categories of a dimension" (Felder and Spurlin, 2005).

"Students learn differently, it is obvious to most psychologists, but less for teachers" (Rahmatian et al., 2011). Felder and Spurlin (2005) emphasize on a teaching/learning methods combining al other ways, either compatible or incompatible, with learners styles.

Having been in an Iranian FFL learning context, the style we find among most learners is called authority-oriented according Willing (1994) that Wong and Nunan (2011) define as a style where the learner expects an explanation for everything. In this tendency, writing and reading activities are used. Besides, listening is not excluded. What makes this style peculiar is the presence of the visual channel that requires everything to be passed under the eyes to be learned. Indeed, the search results will clarify better the learning styles of the Iranian people by gender.

What could better define the behavior of men and women in their learning is the roles that each gender assume in society and before that, education which everyone gets since childhood. All these factors influence their personality and character. General attributes like characteristics which exists with genders, is that women are verbally more capable, while men have better visual and spatial abilities. This difference, according to López Rúa (2006) is explained by the brain functions in both genders.

Previous research determines that women have a verbal tendency and thereafter better and better participation in the collective activities, whilst men are more visual in their learning styles. Besides, Ashrafi and Jahanseir (2011), citing the Koran (1971) and Hunt (1992) on their article, declare the idea that "the inductive approach requires strong verbal skills" to fully activate its cognition in order to discover new things. This can cause us to prejudge the main question of this research that seeks to explore the role of gender in the selection of an inductive or deductive learning, and say that women tend rather to induction and consider that men refer to deduction. But 
wishing to avoid any imprudence in the results, we will base our research on a field study from questionnaire chosen as a research tool, Index of Learning Styles (ILS), whose reliability and validity have already been proven because of the huge load done and inclusion of 44 questions. Felder and Spurlin assert the validity of this model (2005). They insist on the reliability, validity and correctly vision of the concerned questionnaire.

The readers of this research are invited to find it in appendix. Thus, for discovering the learning styles of Iranian learners of FFL according to gender, we would conclude the preferred approach of both genders and assign him, perhaps, one of the components of the dichotomy of induction/deduction.

The website Psychomedia, where we apply the questionnaire, is used only for the questionnaire concerning learning styles by simultaneous score finding.

\section{Research Questions}

1) Is there a categorization of learning styles by gender? If so, in what style dimensions each kind is gathered?

2) What is the level of significance of the gender variable in the choice of an inductive/deductive learning?

3) What constitutes solicitation degree each approach among Iranians?

\section{Research Methodology}

To verify the gender variable in the choice of an inductive or deductive learning styles, a questionnaire (see appendix) was utilized which is a descriptive and experimental methodology realized by quantitative study. We chose our corpus among students of FFL, graduates or students of master or $\mathrm{PhD}$ in Iranian universities. We observe some researchers such as Felder and Spurlin (2005) found that the learning style preferences can be affected by students' educational experiences. In order not to limit the statistical society, the number of students was raised to 44 . The results of participants will be analyzed by the SPSS software and will be shown in figures. Furthermore, a secondary target in this study and further evidence of the use of ILS model is to integrate the inductive approach, with all its desirable impact on learning, which is considered remote or absent from the curriculum in the learning styles of each gender. And this is to prevent frustration for some. "A better way to motivate students is inductive teaching, in which the instructor begins by presenting students with a specific challenge, such as experimental data to interpret, a case study to analyze, or a complex real-world problem to solve" (Prince \& Felder, 2007).

\section{Results and Discussion}

The significant reports of six relationships that are research's main concern will be presented here. Besides, the analytical explanations of statistics will be specified on this section. Then the contradictions between the background of the subject and the research data will be discussed. The results will be visualized by figures at the end of research.

Comparing the results of the 44 completed questionnaires, including 22 men and 22 women, there was a balanced use of active and reflexive styles in both genders (Figures 1 and 2). However, the active style has had a greater share among women. This balance also happens in the second dichotomy: sensing/intuitive. This time, the answers show a more feminine solicitation of sensing style versus a more masculine bias of the intuitive style. This is where the real difference in the choice of two types of learning styles lies. As for the visual and verbal styles, we found a moderate preference of the visual style in men, and a strong preference in the opposite gender. The results show that both genders are more visual; which also explains the practice of visual intelligence among Iranians. The small difference in the use of verbal style in both genders leads to the conclusion that men seeking for verbal style a little more. Regarding the latter two types, sequential and global, we declare that a balance between the two arises: men are slightly more sequential and somewhat less global. Here, a contradiction appears: "boys, compared with girls, have generally more visual learning styles and girls, compared to boys, have more verbal sequential learning styles" (Rahmatian \& Otroshi, 2007). However, without going into comparisons of trends in both genders, we find some contradictions that consider men as global and women as visual. 


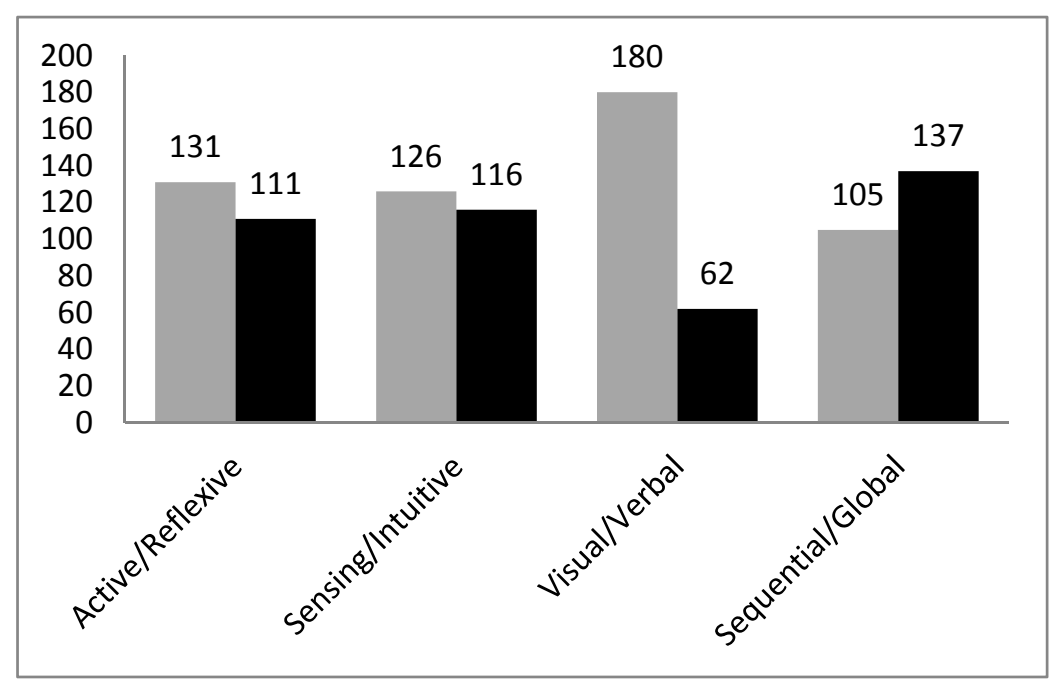

Figure 1. Responses to each division dichotomy of styles in women

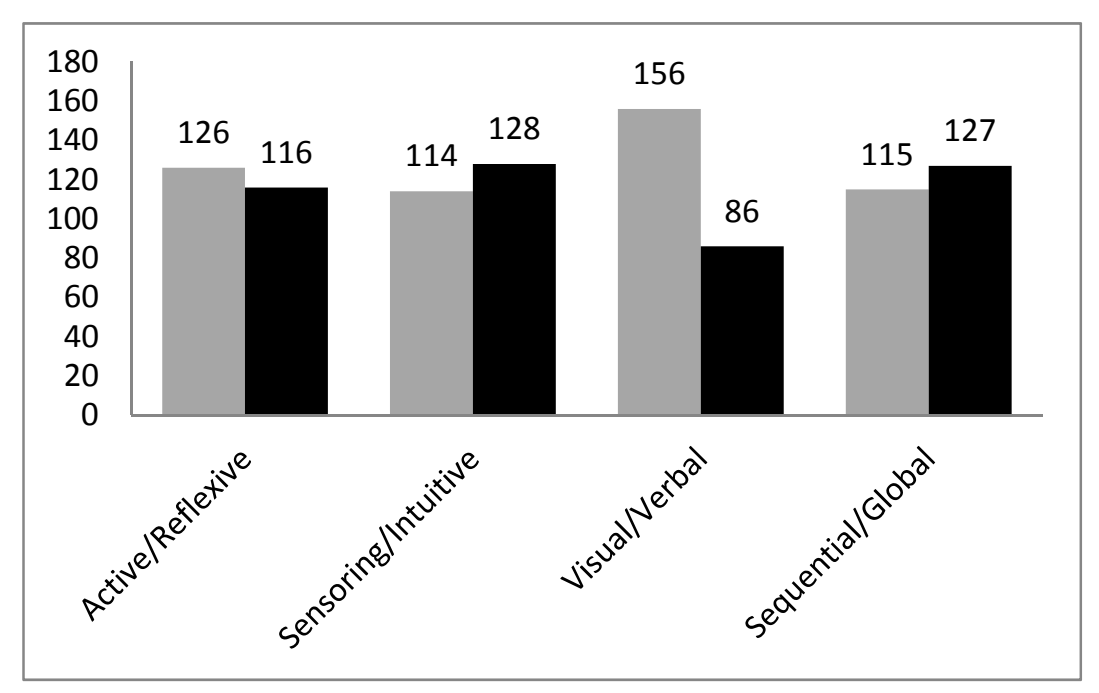

Figure 2. Responses to each division dichotomy of styles in men

Referring to Figures 3 and 4, we conclude that women have greater ease when the learning environment promotes the use of active, intuitive, visual and global styles. Furthermore, it was concluded that they will face difficulties when the learning environment is not conducive to the use of reflexive, intuitive and visual styles. This explains the strong preference for these styles in this gender. 


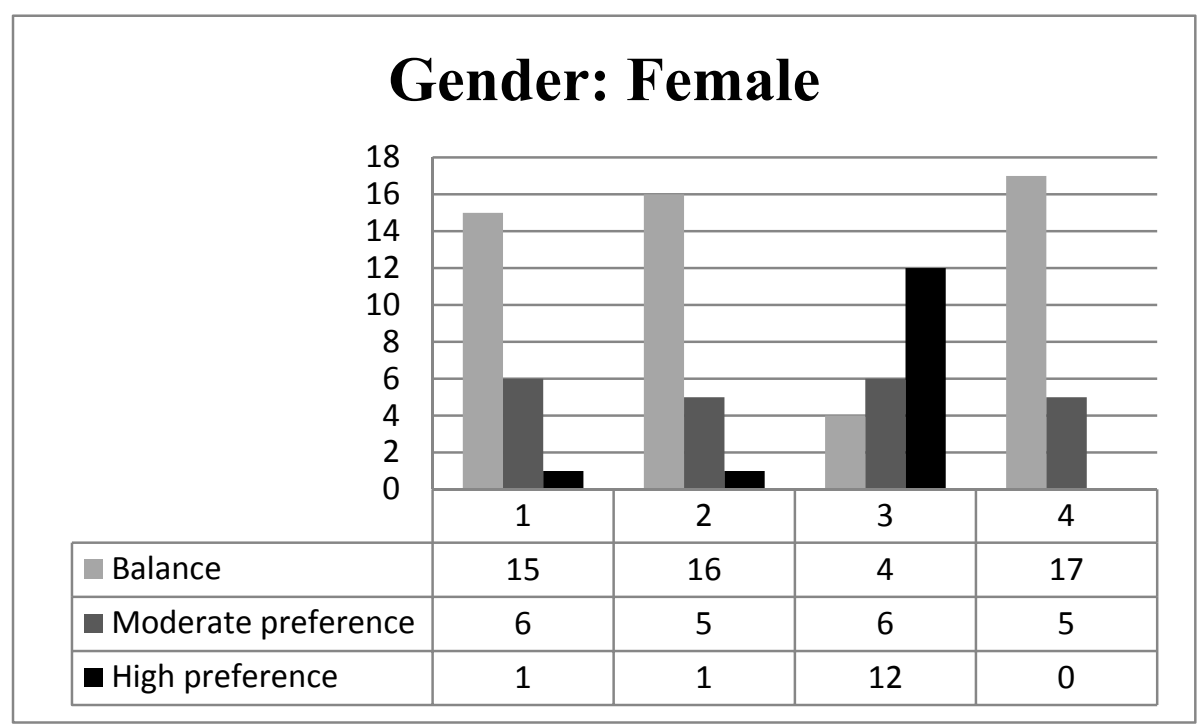

Figure 3. Degree of using learning styles in women

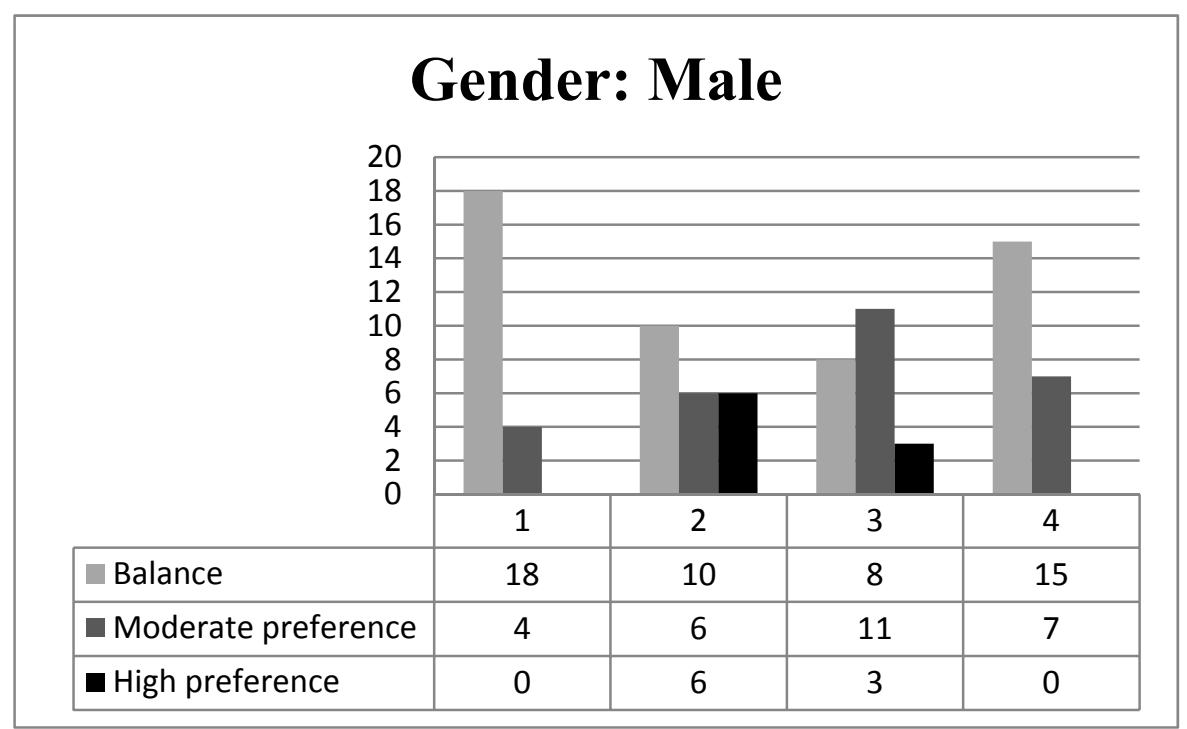

Figure 4. Degree of using learning styles in men

In men, there will be greater ease when the learning environment promotes the use of style both active and reflexive, both sensing and intuitive, visual and global. The problems appear when the learning environment is not conducive to the use of intuitive and visual styles, for which they express a strong preference.

In order to examine the role of the deduction and induction in learning among both genders, their responses were analyzed in accordance with two classes, the first leads to the induction and the other to the deduction: 1. Active, intuitive and sequential styles; 2. Reflective, sensing and global styles. The numbers on figure (5) show that women, either in their way or in a mixed gender, are more deductive. The opposite situation was observed in the male gender: induction is dominant. Excluding gender, the outcome of the analysis reported the dominance of the deduction among Iranians with a little tinge of using induction. 


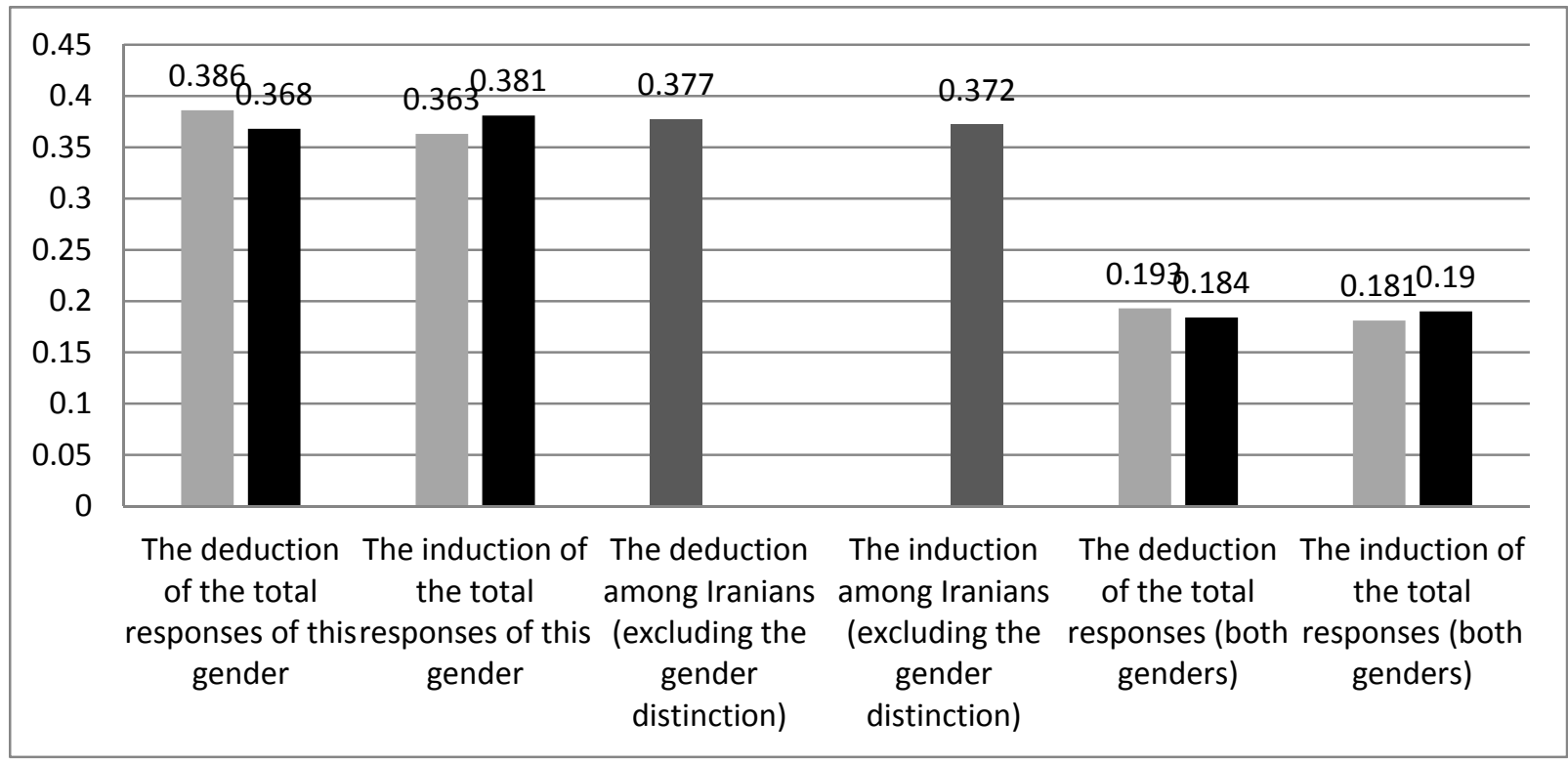

\section{Woman $\square$ Man}

Figure 5. The presence (\%) of inductive and deductive approaches among Iranians

The idea about induction requires a higher capacity of argumentation and discussion. According to De Bie's, "girls are supposed to be better at expressing themselves" (1987, quoted by López-Rúa, 2006). This explains the desire for induction or its success in women. Despite this, we can also designate a deductive preference with them: "girls, who are evidently somewhat more sensitive to negative comments, are more concerned about performing in the right way ordained by the teacher" (ibid.: 108). This contradiction could be resulted from the education they receive that affects their learning behavior. This explanation might well assert our results which consider men more inductive than women. Besides, by this test, the analysis was supported on the mental characteristics of men and women, some in comparison with others, rather than describing their general character. That said, we do not want to associate all of high or low intelligence to this or claim that the deduction would be the most advantageous with a weaker intelligence or otherwise, learning would be the same level.

The steps from the detail to the general attract people with more motivation to organize their knowledge better and more actively. It seems that girls show themselves more motivated in foreign languages learning (Rahmatian \& Otroshi, 2007). It is noteworthy that motivation and induction are compatible, but the presence of motivation in deductive learners- the style considered by women today- should not be neglected.

\section{Conclusion}

The target of this research was to find out trends of Iranian learners of FFL in their choice of inductive and deductive approaches following their gender. Thus, seeking to better argue the tendency of each gender to induction or deduction in learning, the learning styles of each gender was studied first, the conclusion was drawn from the analysis of the Felder and Silverman questionnaire. Regarding four dichotomies that have learning styles among the directors of the questionnaire, the attention was focused on those that lead to two approaches in question. In addition, we solicited the learning styles of David Kolb that intensified our reflection in the establishment of relations between inductive and deductive approaches and styles. That said, we will not specify styles to a single gender, saying that some are male, others are female or that all learners share the same styles. As with Kolb in the learning process, the styles are interrelated. The only difference is that with Kolb, we have a circle; a starting point and an ending point. Rather, the characteristics of each phase bring us closer to the correlation between the two styles.

The four steps outlined by Kolb in a cycle in the learning process consist of concrete experience, reflective observation, abstract conceptualization and active experimentation. These phases respectively refer to divergent styles, assimilating, convergent and accommodating.

Paralleling the four styles of Kolb and those Felder's four dichotomies, the divergent style of learners on two 
parts can be described: intuitive and active; assimilator ones on reflective and intuitive; convergent ones on reflective and sensing, and accommodative learners on sensing and active. Therefore, students with a preference, without identifying the degree for the active, intuitive and sequential style learn better by following the inductive approach. The deductive approach creating desire for many Iranian teachers and learners, we are corresponding it to the remainder of styles, that is to say, the reflexive, sensing and global styles. We should add that in our analysis, we have omitted the visual and verbal styles, having found the least share in common between them and the inductive and deductive approaches.

\section{Acknowledgements}

The authors, hereby, would like to thank the PhD and MA students of the universities in Tehran who helped us with the questionnaire and kindly responded to the questions. We also would like to thank the professors of Tarbiat Modares University for their constructive help and support.

\section{References}

Alzu'bi, M. A. (2015). Effectiveness of Inductive and Deductive Methods in Teaching Grammar. Advances in Language and Literary Studies, 6(2), 187-193.

Ashrafi, S., \& Jahanseir, K. H. (2011). The Impact of Inductive and Analogical Teaching Methods on Students' Mathematic Scores in Islamic Azad University of Maragheh. Research in Curriculum Planning, 8(1, 2), 28, $29,63-71$.

Besse, H. (1985). Méthodes et pratiques des manuels de langue. Paris: Didier.

Bodéüs, R. (2002). Aristote, une philosophie en quête de savoir. Paris: VRIN.

Boulton, A. (2010). Consultation de corpus et styles d'apprentissage. Cahier de l'APLIUT, 29(1), 98-115. https://doi.org/10.4000/apliut.967

Chalipa, S. (2013). The Effect of Inductive vs. Deductive Instructional Approach in Grammar Learning of ESL Learners. International Researchers, 2(2), 178-186.

Defays, J.-M., \& Deltour, S. (2003). Le français langue étrangère et seconde: Enseignement et apprentissage. Bruxelles: MARDAGA.

Ellis, R. (2008). The Study of Second Language Acquisition (2nd ed.). New York: Oxford University Press.

Felder, R. M., \& Henriques, E. R. (1995). Learning and Teaching styles In Foreign and Second Language Education. Foreign Language Annals, 28(1), 21-31. https://doi.org/10.1111/j.1944-9720.1995.tb00767.x

Felder, R. M., \& Silverman L. K. (1988). Learning and Teaching Styles in Engineering Education. Engr. Education, 78(7), 674-681.

Felder, R. M., \& Silverman L. K. (1988a). Learning and Teaching Styles in Engineering Education. Engr. Education, 78(7), 674-681.

Felder, R. M., \& Spurlin, J. (2005). Applications, Reliability and Validity of the Index of Learning Styles. Int. J. Engng Ed, 21(1), 103-112.

Goodman, N. (1946). A Query on Confirmation. Journal of Philosophy, 43, 383-385. https://doi.org/10.2307/2020332

Griggs, P., Carol, R., \& Bange, P. (2002). La dimension cognitive dans l'apprentissage des langues étrangères. Revue française de linguistique appliquée, VII(2), 25-38.

Haight, C. E., Herron, C., \& Cole, S. P. (2007). The Effects of Deductive and Guided Inductive Instructional Approaches on the Learning of Grammar in the Elementary Foreign Language College Classroom. Foreign Language Annals, 40(2), 288-310. https://doi.org/10.1111/j.1944-9720.2007.tb03202.x

López, R. P. (2006). The sex variable in foreign language learning: an integrative approach. Porta Linguarum, 6 , 99-114.

Michel, M. (2002). La démarche inductive en pédagogie. Le portique, 9, 1-4.

Musgrave, A. (2009). Popper and hypothetico-deductivism. Handbook of the History of Logic, 10, 205-234.

Pellissier-Tanon, A. (2011). L'induction, au cœur du dilemme des savoirs en science de gestion. Stratégies, Actualités et futurs de la recherche, 55-66. Paris: Vuibert, FNEGE.

Prince, M., \& Felder, R. (2007). The Many Faces of Inductive Teaching and Learning. Journal of College Science Teaching, 36(5), 14-20. 
Puren, Ch. (2001a). Méthodes et constructions méthodologiques dans l'enseignement et l'apprentissage des langues. Les langues modernes, 1, 68-70. Paris: APLV.

Rahmatian, R., \& Otroshi, M. H. (2007). Considering the Role of Gender in Foreign Language Learning Process. Human Sciences, 55, 147-158.

Rahmatian, R., Molasadeghi, M., \& Mehrabi, M. (2011). Les intelligences multiples et l'apprentissage du FLE (Étude du cas chez les apprenants iraniens). Recherches en Langue et Littérature françaises, Revue de la faculté des Lettres, Année, 5(8), 55-74.

Roland, Ch. (2014). L'inductivisme. Retrieved from http://www.freesciences.be/lascience3.php

Silverman, L. K. (2002). Upside-Down Brilliance: The Visual-Spatial Learner. Denver: DeLeon Publishing.

Takimoto, M. (2008). The Effects of Deductive and Inductive Instruction on the Development of Language Learners' Pragmatic Competence. The Modern Language Journal, 92, 369-386. https://doi.org/10.1111/j.1540-4781.2008.00752.x

Tardieu, C. (2014). Résurgence et rémanence des méthodes au fil du temps: Réflexion sur les méthodologies de l'enseignement de l'anglais en France. Recherche et pratiques pédagogiques en langues de spécialité [online], XXXIII(2). https://doi.org/10.4000/apliut.4373

Vincent, F., \& Lefrançois, P. (2013). L'opposition inductif/déductif en enseignement de la grammaire: Un débat à nuancer. Revue des sciences de l'éducation, 39(3), 471-490. https://doi.org/10.7202/1026309ar

Wong, L. C., \& Nunan, D. (2011). The learning styles and strategies of effective language learners. System, 39, 144-163. https://doi.org/10.1016/j.system.2011.05.004

Xin, J. (2012). The Effect of Integrating Inductive Approach and Deductive Approach with Multimedia Assistance into Acquisition of subjunctive Mood. Sino-US English Teaching, 9(9), 1510-1515.

Zhuya, W. (2011). Une pédagogie mettant l'accent sur l'autonomie de l'apprenant. Synergies Chine, 6, 141-149.

\section{Appendix}

\section{Questionnaire:}

1. I understand something better after I

(a) try it out.

(b) think it through.

2. I would rather be considered

(a) realistic.

(b) innovative.

3. When I think about what I did yesterday, I am most likely to get

(a) a picture.

(b) words.

4. I tend to

(a) understand details of a subject but may be fuzzy about its overall structure.

(b) understand the overall structure but may be fuzzy about details.

5. When I am learning something new, it helps me to

(a) talk about it.

(b) think about it.

6. If I were a teacher, I would rather teach a course

(a) that deals with facts and real life situations.

(b) that deals with ideas and theories.

7. I prefer to get new information in

(a) pictures, diagrams, graphs, or maps. 
(b) written directions or verbal information.

8. Once I understand

(a) all the parts, I understand the whole thing.

(b) the whole thing, I see how the parts fit.

9. In a study group working on difficult material, I am more likely to

(a) jump in and contribute ideas.

(b) sit back and listen.

10. I find it easier

(a) to learn facts.

(b) to learn concepts.

11. In a book with lots of pictures and charts, I am likely to

(a) look over the pictures and charts carefully.

(b) focus on the written text.

12. When I solve math problems

(a) I usually work my way to the solutions one step at a time.

(b) I often just see the solutions but then have to struggle to figure out the steps to get to them.

13. In classes I have taken

(a) I have usually gotten to know many of the students.

(b) I have rarely gotten to know many of the students.

14. In reading nonfiction, I prefer

(a) something that teaches me new facts or tells me how to do something.

(b) something that gives me new ideas to think about.

15. I like teachers

(a) who put a lot of diagrams on the board.

(b) who spend a lot of time explaining.

16. When I'm analyzing a story or a novel

(a) I think of the incidents and try to put them together to figure out the themes.

(b) I just know what the themes are when I finish reading and then I have to go back and find the incidents that demonstrate them.

17. When I start a homework problem, I am more likely to

(a) start working on the solution immediately.

(b) try to fully understand the problem first.

18. I prefer the idea of

(a) certainty.

(b) theory.

19. I remember best

(a) what I see.

(b) what I hear.

20. It is more important to me that an instructor

(a) lay out the material in clear sequential steps.

(b) give me an overall picture and relate the material to other subjects.

21. I prefer to study

(a) in a study group. 
(b) alone.

22. I am more likely to be considered

(a) careful about the details of my work.

(b) creative about how to do my work.

23. When I get directions to a new place, I prefer

(a) a map.

(b) written instructions.

24. I learn

(a) at a fairly regular pace. If I study hard, I'll "get it."

(b) in fits and starts. I'll be totally confused and then suddenly it all "clicks."

25. I would rather first

(a) try things out.

(b) think about how I'm going to do it.

26. When I am reading for enjoyment, I like writers to

(a) clearly say what they mean.

(b) say things in creative, interesting ways.

27. When I see a diagram or sketch in class, I am most likely to remember

(a) the picture.

(b) what the instructor said about it.

28. When considering a body of information, I am more likely to

(a) focus on details and miss the big picture.

(b) try to understand the big picture before getting into the details.

29. I more easily remember

(a) something I have done.

(b) something I have thought a lot about.

30. When I have to perform a task, I prefer to

(a) master one way of doing it.

(b) come up with new ways of doing it.

31. When someone is showing me data, I prefer

(a) charts or graphs.

(b) text summarizing the results.

32. When writing a paper, I am more likely to

(a) work on (think about or write) the beginning of the paper and progress forward.

(b) work on (think about or write) different parts of the paper and then order them.

33. When I have to work on a group project, I first want to

(a) have "group brainstorming" where everyone contributes ideas.

(b) brainstorm individually and then come together as a group to compare ideas.

34. I consider it higher praise to call someone

(a) sensible.

(b) imaginative.

35. When I meet people at a party, I am more likely to remember

(a) what they looked like. 
(b) what they said about themselves.

36. When I am learning a new subject, I prefer to

(a) stay focused on that subject, learning as much about it as I can.

(b) try to make connections between that subject and related subjects.

37. I am more likely to be considered

(a) outgoing.

(b) reserved.

38. I prefer courses that emphasize

(a) concrete material (facts, data).

(b) abstract material (concepts, theories).

39. For entertainment, I would rather

(a) watch television.

(b) read a book.

40. Some teachers start their lectures with an outline of what they will cover. Such outlines are

(a) somewhat helpful to me.

(b) very helpful to me.

41. The idea of doing homework in groups, with one grade for the entire group,

(a) appeals to me.

(b) does not appeal to me.

42. When I am doing long calculations,

(a) I tend to repeat all my steps and check my work carefully.

(b) I find checking my work tiresome and have to force myself to do it.

43. I tend to picture places I have been

(a) easily and fairly accurately.

(b) with difficulty and without much detail.

44. When solving problems in a group, I would be more likely to

(a) think of the steps in the solution process.

(b) think of possible consequences or applications of the solution in a wide range of areas.

\section{Copyrights}

Copyright for this article is retained by the author(s), with first publication rights granted to the journal.

This is an open-access article distributed under the terms and conditions of the Creative Commons Attribution license (http://creativecommons.org/licenses/by/4.0/). 